\title{
Visual depictions of female genitalia differ depending on source
}

Helena Howarth, Volker Sommer and Fiona M Jordan

Med Humanities 2010 36: 75-79

doi: 10.1136/jmh.2009.003707

Updated information and services can be found at:

http://mh.bmj.com/content/36/2/75.full.html

\section{These include:}

References This article cites 24 articles, 4 of which can be accessed free at: http://mh.bmj.com/content/36/2/75.full.html\#ref-list-1

Email alerting Receive free email alerts when new articles cite this article. Sign up in the service box at the top right corner of the online article.

Notes

To request permissions go to:

http://group.bmj.com/group/rights-licensing/permissions

To order reprints go to:

http://journals.bmj.com/cgi/reprintform

To subscribe to BMJ go to:

http://journals.bmj.com/cgi/ep 


\title{
Visual depictions of female genitalia differ depending on source
}

\author{
Helena Howarth, ${ }^{1}$ Volker Sommer, ${ }^{1}$ Fiona M Jordan ${ }^{2}$
}

- Supplementary tables 1 and 2 are published online only. To view these files please visit the journal online (http://mh.bmj. com).

'Department of Anthropology, UCL, London, UK

${ }^{2}$ Max Planck Institute for Psycholinguistics, Nijmegen, The Netherlands

\section{Correspondence to}

Fiona M Jordan, Max Planck Institute for Psycholinguistics, PB 310, Nijmegen, 6500 AH, The Netherlands: fiona.jordan@mpi.nl

Accepted 7 September 2010

\section{ABSTRACT}

Very little research has attempted to describe normal human variation in female genitalia, and no studies have compared the visual images that women might use in constructing their ideas of average and acceptable genital morphology to see if there are any systematic differences. The objective of the present work was to determine if visual depictions of the vulva differed according to their source so as to alert medical professionals and their patients to how these depictions might capture variation and thus influence perceptions of 'normality'. A comparative analysis was conducted by measuring (a) published visual materials from human anatomy textbooks in a university library, (b) feminist publications (print and online) depicting vulval morphology and (c) online pornography, focusing on the most visited and freely accessible sites in the UK. Post hoc tests showed that labial protuberance was significantly less $(p<0.001$, equivalent to approximately $7 \mathrm{~mm}$ ) in images from online pornography compared to feminist publications. All five measures taken of vulval features were significantly correlated $(p<0.001)$ in the online pornography sample, indicating a less varied range of differences in organ proportions than the other sources where not all measures were correlated. Women and health professionals should be aware that specific sources of imagery may depict different types of genital morphology and may not accurately reflect true variation in the population, and consultations for genital surgeries should include discussion about the actual and perceived range of variation in female genital morphology.

\section{INTRODUCTION}

Labial reductions are becoming more prevalent in Britain ${ }^{1}$ : NHS-funded operations increased from 400 to 1100 between 2002 and $2008 .^{2}{ }^{3}$ More generally, elective or cosmetic surgical procedures involving female genitalia have undergone an apparent increase in popularity, perhaps attributable to increased media coverage. ${ }^{4}$ This is despite the lack of data on clinical effectiveness and any reported preoperative reference to normative data. ${ }^{3}$ These surgeries vary in their nature, but women in Britain who seek medical treatment generally request reductions that result in no protuberance of the labia minora from between the labia majora. ${ }^{2}$

Social taboos on sexual subjects mean that many women are unable to identify the features of their own genitalia or feel uncomfortable when speaking about their vulval morphology to a doctor. ${ }^{5}$ Thus, many women may lack knowledge of the morphology and functions of the parts of their genitalia, and how shapes and proportions vary from woman to woman. We have been unable to find information in the literature that indicates how much women are aware of the variability of female genital morphology. Individuals may gain knowledge from seeing other people's bodies (eg, family members, sexual partners, in changing rooms), but female genital morphology is often difficult to assess by casual glance due to coverage by pubic hair and the relative obstruction of female genitalia in a standing position. It is likely then that other sources such as written descriptions, drawings, photographs or films contribute significantly to an individual's understanding of average and acceptable genital morphology.

Evidence now shows that media representations of health-related information can impact on people's attitudes and beliefs, for example, on perceived prevalence and risk of disease ${ }^{6}$ and on the uptake of cancer screening programs. ${ }^{7} 8$ Visual messages about health-related behaviours may also be conveyed more covertly through, for example, advertising. ${ }^{9}{ }^{10}$ With respect to genital morphology, even individuals who are unconcerned about their genitalia are likely to form a concept of 'normality' from multiple sources of information, and the construal of 'normal' may play some part in determining to what extent women problematise their own bodies. If the sources of information that individuals access about variation in genitalia contain some bias or skew towards certain morphologies, it is important that healthcare workers are able to communicate those biases to women who express concern about their bodies or who may wish to undergo elective genital surgery based on non-representative concepts of female variation in morphology. By 'bias', we only refer to systematic (not necessarily purposeful) deviations from the true range of variation in the population. This nature of this variation is, however, elusive. To date the only study attempting to characterise the variation in normal female genitalia is based on a small sample of 50 premenopausal women in England undergoing gynaecological procedures not involving the external genitalia; ${ }^{11}$ a similar study in Turkey looked at differences between premenopausal and postmenopausal women. ${ }^{12}$

Here, we investigated potential differences in three genres of imagery which women might encounter in constructing their ideas of average and acceptable genital morphology: online pornography, educational textbooks and feminist publications. We did not include resources or websites specifically targeted at women searching for information on surgeries such as labial reduction, as we were interested in the sources of imagery that individuals might encounter before taking this step. Measurements of labial protuberance and genital 
morphology ratios were calculated for all images and compared across the sources and, where possible, to the physical measurements of English women. ${ }^{11}$

\section{METHODS \\ Sample}

We identified three genres of genital images that were widely available and accessible to the general public: online pornography, educational materials in anatomy textbooks and feminist publications.

\section{Online pornography ( $\mathrm{n}=98$ images)}

The sample came from the top three free pornography websites visited by users of Microsoft's Internet Explorer browser software in the UK in 2008. ${ }^{13}$ All three sites allow free posting of content, including commercial pornography and 'user-generated content'. Two sites, RedTube ${ }^{14}$ and YouPorn, ${ }^{15}$ presented each image or video along with a user rating. This rating was an arbitrary personal preference aggregate set by viewers and generally took the form of a five-point scale. We used this rating to ascertain if there was systematic bias concerning images rated highly by viewers, and to choose the images; highly rated images were preferentially used. The third site, PornHub, ${ }^{16}$ had no rating facility so images were selected randomly from image galleries.

\section{Anatomy textbooks ( $\mathrm{n}=29$ images)}

The sample was drawn from all the general anatomy texts in the University College London Science Library on 28 May 2008. Our rationale was to strike a balance between technical gynaecology material available at specialist medical libraries and the sorts of images one could see in home-health texts or internet illustrations; we reasoned that a university level anatomy collection might meet this balance. We have no evidence that this is truly the case, but we found a good deal of image 'recycling' in medical textbooks and thus inferred that publishers would be likely to reuse already commissioned illustrations for different sorts of volumes. Less than half (92/220) of the general anatomy textbooks included an image of a vulva, and of those the majority of images were too small to measure or used across multiple books. The final sample of 29 included 3 photographs, but the majority were line drawings. More detail on the books used in the sample can be found in the supplementary material.

\section{Feminist publications ( $\mathrm{n}=126$ images)}

This sample came from three sources: the website Vulvology ${ }^{17}$ (http://www.erogenousdot.com) and two books, Petals and Femalia. ${ }^{18} 19$ These were chosen as they are accessible in print or online on a permanent basis, unlike for example art exhibits, ${ }^{20}$ and at least one was free. There may be some authorial bias in the images within this sample, as Karras ${ }^{18}$ took all his own photos and Blank ${ }^{19}$ used those of only four photographers. The creator of Vulvology does not state where the photographs originate; hence, some may have originally been taken as pornographic images. Importantly however, all authors state that they aimed to show the diversity of vulvas; Blank specifically points to the 'variation in style, colour, size and proportion' contained in the volume. ${ }^{19}$

\section{Measurements Procedure}

We took measurements from screen images (static or paused film clip on a 15-inch monitor) or book illustrations/photos using a standard millimetre ruler. We used a minimum image size of
200 pixels/72 dpi on the shortest side for digital images $(70 \mathrm{~mm}$ for print images). We used all images photographed from an angle that allowed measurement of the lengths of different features. If image resolution was too poor to observe more than two-thirds of our measures, that image was not used. The final samples included a diverse range of body types and ethnicities, though we cannot claim they are statistically representative of any one population.

One author $(\mathrm{HH})$ recorded all measurements onto a spreadsheet for statistical analysis while another (FJ) measured a random sample $(10 \%)$ of static and video images to assess measurement reliability. The correlation between these two sets of measurements was very high (0.98), and on only $6 \%$ of images was there disagreement as to whether some measurements could be accurately taken. Data were originally gathered for a project on genital variation, and while measurements were not taken blind as to sources, they were recorded before the specific comparisons reported here were formulated. Due to the varying nature of the images we were unable to compare vulval pigmentation. We were also unable to measure labial asymmetry; the judgement of asymmetry was hampered by differing perspectives and positions in the images.

\section{Protuberance of the labia minora from within the labia majora}

Two studies report measurements of labia minora width in healthy women. A sample of English women has a range of 7-50 mm (mean 21 19.4$),{ }^{11}$ while for Turkish women this range is $11-30 \mathrm{~mm}$ (mean 17.9 \pm 4.1 ). ${ }^{12}$ The level of protuberance may be a compromise between being large enough to act as a barrier, preventing alien objects from entering the vestibule or vagina, but not so large as to indicate negative health conditions such as overandrogenisation $^{21}$ or urinary incontinence. ${ }^{22}$ We used the English sample ${ }^{11}$ findings as a guideline. Labia minora protuberance was measured by eye on a $1-5$ scale where each interval corresponded to an estimated $10 \mathrm{~mm}$ increase in protuberance. Vulvas in category 1 were estimated to have $10 \mathrm{~mm}$ or less (ie, labia minora not visible) and those in category 5 over $40 \mathrm{~mm}$ protuberance. Categories 2 and 3 corresponded to the mean $\pm 1 S D$. from the British sample. ${ }^{11}$ We used a Kruskal-Wallis test for rank differences with Bonferroni post hoc correction to test for differences in mean protuberance.

\section{Measurement ratios of genital morphology}

Five quantitative measures were taken to an accuracy of $1 \mathrm{~mm}$ : clitoral hood length, distance from clitoral hood to urethra, labia minora length, labia majora length and perineum length following Lloyd et al; however, we measured the distance from the tip of the clitoral hood (not tip of clitoris) to the urethra. Not all measures could be taken from each image for reasons including incomplete coverage of the vulval area, fingers or extensive pubic hair obscuring borders between features and protruding labia minora that hid the urethra within the vestibule. We calculated Pearson correlation coefficients between all the five raw measures, and we tested for normality of distribution using the one-sample Kolmogorov-Smirnov test. As measurements were taken from non-standardised images, all quantitative measures were then transformed into ratios of pairs of measures. This standardised value allowed for comparisons between samples and with Lloyd et al.

\section{RESULTS}

The total sample consisted of 253 line drawings or photographs (see supplementary material). 


\section{Labial protuberance}

The percentages of each imagery sample falling into each protuberance categories have different distribution patterns (figure 1). Online pornography and anatomy textbooks both skew towards the less-protruding end of the range; the highprotruding category is only represented in the feminist publications sample. The mean ranks were significantly different as a function of imagery source $(p<0.001)$ and post hoc tests revealed the online pornography and feminist publications samples differed significantly $(p<0.001)$, such that feminist publications samples have a mean protuberance score of 0.67 (95\% CI 0.30 to 1.04$)$ higher than online pornographyapproximately $7 \mathrm{~mm}$.

\section{Measurement ratios of genital morphology}

All five measures were correlated with each other at the level of the whole sample $(\mathrm{p}<0.001)$ and within the online pornography sample $(p<0.001)$. Two anatomy textbooks measures and two feminist publications measures were uncorrelated; all others were correlated $p<0.05$. The online pornography sample thus indicates a less varied range of morphologies. When we divided the online pornography sample into those from the "highly rated' sources and the unrated sources we found no clear biases.

All but 1 (labia majora/perineum length in online pornography) of the 30 within-sample measurement ratios were distributed normally, but when the 3 imagery sources were pooled together, 6 of these 10 combined ratios were distributed non-normally (table 1). This contrast indicated a between-group difference and 1-way analysis of variance (ANOVA) revealed a significant difference in means in 6 out of 10 ratios (table 1 ). Table 1 shows that for each ratio that has a significant betweensample difference, the smallest mean ratio belongs to the anatomy textbook sample. Hence the medical illustrations show
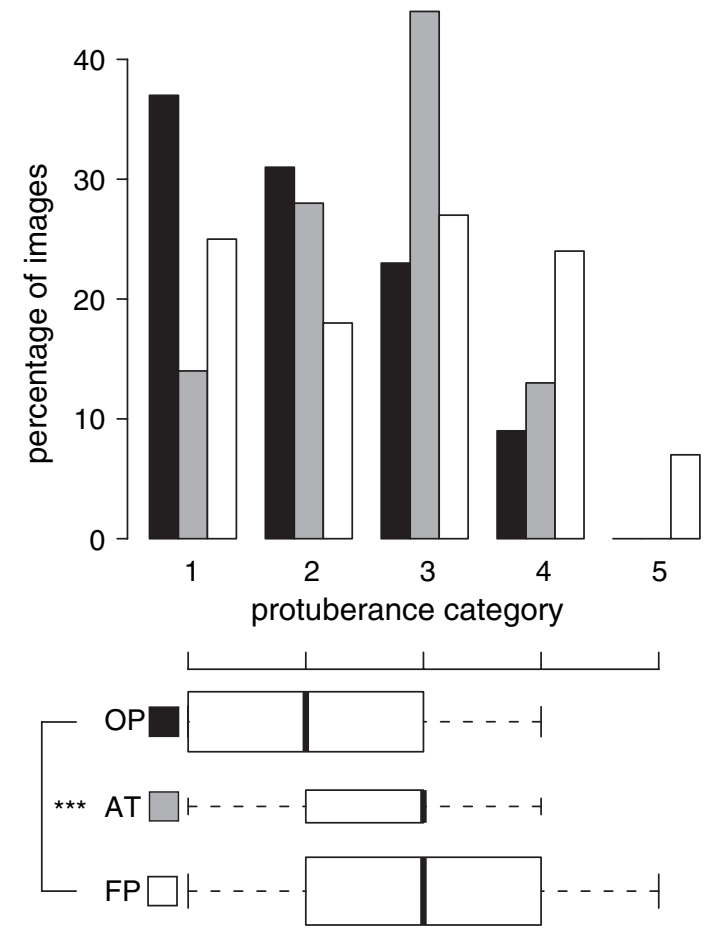

Figure 1 Labia minora protuberance measurements. Bar chart (top) shows the percentage of images falling into each protuberance category (see text) by source. Box plots show quartiles, ranges and means. $\mathrm{AT}$, anatomy textbooks (grey bars); FP, feminist publications (white bars); $\mathrm{OP}$, online pornography (black bars). ${ }^{* *} \mathrm{p}<0.001$. reduced proportions in many of these measures, including threequarters of the ratios involving the labia minora. Additionally, for each ratio where there is a significant difference between the feminist publication sample and others, the feminist publication measures are the largest. We also compared three measurement ratios to the results from Bsaran et al ${ }^{12}$ that were appropriate. Clitoris to urethra/labia minora length (0.52) was closest to the feminist publication sample, clitoris to urethra/perineum length (1.03) was closest to the online pornography sample and labia minora/perineum length was closest (1.85) to the textbook sample.

\section{DISCUSSION}

In a comparative survey of 253 images of female genitalia, we found that online pornography depicts significantly less protuberant labia minora than imagery from feminist publications. Mean protuberance observed in genital illustrations from anatomy textbooks is not significantly different from either of the other sources, though the range of the measures is more restricted. By comparing measurement ratios of genital morphology, we found that medical illustrations also show reduced proportions overall compared to the other two sources. All raw measures for online pornography were significantly correlated, indicating a less varied range in terms of differences in organ proportions.

To our knowledge, this study is the first quantitative characterisation of the range of female genital morphology depicted in different sources of visual imagery (but see some similarities in Schick et al, ${ }^{23}$ discussed below). Studying body imagery can help us understand how individuals (women seeking health advice and service providers) create their concept of average and acceptable morphology. Demonstrating that there may be significant differences between sources, as we have performed here, is thus crucial. For example, medical illustrations are constrained by their educational function of detailing the anatomy of the female vulva: the labia minora must protrude from the labia majora in order to be labelled, but not so much that they obscure other features. That online pornography images show less protuberant labia minora-in effect reflecting the morphology that women seeking labial reductions state they want ${ }^{2}{ }^{3}$-and that these surgeries are increasing does not imply a causative link. For instance, pornography may reflect some preexisting preference for small labia minora: a recent longitudinal survey of Playboy centrefold models scored images for labia majora visibility and size, and found that the labia minora were only visible in $7 \%$ of images. ${ }^{23}$ Despite these limitations, including that we had no controls for factors such as age and ethnicity, our approach was simple and replicable, and we had high agreement on measurements and each imagery sample was highly internally correlated on the measurement ratios.

No study that examines genital morphology across imagery sources exists for comparison to these results. Few real-life measurement samples are available, so we are also unable to say which imagery source reflects the general population most closely. Bsaran et al's Turkish sample is perhaps more ethnically homogenous, ${ }^{12}$ so Lloyd et al $^{11}$ is the most suitable comparison. Our means for all images combined are similar to Lloyd et al despite the differences in methodology (pictures compared to people), being 0.1 ratio units distant in four cases and 0.2 in a further two cases of the combined sample mean. Table 1 indicates that the mean ratios in medical illustrations most closely approximate the mean ratios that can be calculated from Lloyd et al's results, but we cannot make any statistical claims 
Table 1 Measurement ratios compared across the imagery samples showing tests for non-normality, significant one-way analysis of variance (ANOVA) for sample mean differences and ratios of mean measurements $\pm S D$ for each imagery sample, the combined sample and the ratios of means in Lloyd et $a l^{11}$ for comparison. Samples in a column that are significantly different are indicated if they are shaded the same colour and/or enclosed in a box

\begin{tabular}{|c|c|c|c|c|c|c|c|c|c|c|}
\hline & $\mathrm{CH} /$ & $\mathrm{CH} /$ & $\mathrm{CH} /$ & $\mathrm{CH} /$ & $\mathrm{CU} /$ & $\mathrm{CU} /$ & $\mathrm{CU} /$ & MA / & $\begin{array}{l}\mathrm{MA} / \\
\mathrm{PL}\end{array}$ & $\begin{array}{l}\mathrm{MI} / \\
\mathrm{PL}\end{array}$ \\
\hline & $\mathrm{CU}$ & MA & MI & PL & MA & $\mathrm{MI}$ & & & & \\
\hline Non-normality & $* *$ & N.S. & * & $* *$ & N.S. & N.S. & N.S. & $* *$ & $* *$ & ** \\
\hline $\begin{array}{l}\text { Group } \\
\text { difference }\end{array}$ & N.S. & $* * *$ & $* * *$ & $* *$ & ** & * & N.S. & N.S. & N.S. & * \\
\hline
\end{tabular}

Ratios of means

\begin{tabular}{|c|c|c|c|c|c|c|c|c|c|c|}
\hline Online & 1.22 & .27 & .44 & 1.18 & .25 & .37 & 1.09 & 1.56 & 4.50 & 3.01 \\
\hline pornography & \pm .80 & \pm .09 & \pm .22 & \pm .70 & \pm .07 & \pm .10 & \pm .65 & \pm .35 & \pm 2.19 & \pm 1.47 \\
\hline Anatomy & .90 & .17 & .29 & 0.65 & .23 & .37 & .84 & 1.58 & 3.76 & 2.29 \\
\hline textbooks & \pm .64 & \pm .06 & \pm .12 & \pm .70 & \pm .07 & \pm .11 & \pm .36 & \pm .18 & \pm 1.07 & \pm .59 \\
\hline Feminist & .97 & .30 & .48 & 1.19 & .33 & .44 & 1.23 & 1.55 & 4.38 & 2.91 \\
\hline publications & \pm .63 & \pm .12 & \pm .26 & \pm .71 & \pm .17 & \pm .13 & \pm .45 & \pm .41 & \pm 1.86 & \pm 1.16 \\
\hline \multirow[t]{2}{*}{ All sources } & 1.05 & .27 & .44 & 1.10 & .26 & .39 & 1.03 & 1.56 & 4.36 & 2.86 \\
\hline & \pm .71 & \pm .11 & \pm .24 & \pm .68 & \pm .11 & \pm .12 & \pm .54 & \pm .36 & \pm 1.99 & \pm 1.30 \\
\hline Ref. 11 & .67 & .21 & .32 & .61 & .31 & .47 & .91 & 1.53 & 2.97 & 1.94 \\
\hline
\end{tabular}

${ }^{*} \mathrm{p}<0.05 ;{ }^{* *} \mathrm{p}<0.01 ;{ }^{* * *} \mathrm{p}<0.001$.

$\mathrm{CH}$, clitoral hood length; CU, distance from clitoris to urethra; MA labia majora length; MI, labia minora length; PL, perineum length; NS, non-significant.

here, nor can we compare the range of variation. We can compare on labial protuberance measures: the restricted range of textbook illustrations and the lack of moderate to highly protuberant labia minora in the online pornography sample suggests that these sources do not reflect the true variation in the general population. It is likely that the feminist publication sources reflect most closely the approximate range of real variation in labial protuberance; this sample covers all the predefined protuberance categories that we derived from Lloyd et al.

Genital variation is understudied, and we strongly encourage scientific $^{11} 122^{23}$ and educational/artistic initiatives ${ }^{20} 24$ that promote clinical and popular understanding of the range of variation in genital morphology. Here, we were concerned with depictions in sources that may shape the perceived range of variation, therefore imagery samples are justified, but measurements of genital morphology should ideally be taken directly from life. Our preliminary review is the first of its kind but should be extended in sample size and scope to confirm these findings are robust. Ideally, we would like to account for demographic characteristics: for example, only a little is known about within-individual changes in genital morphology, such as menstrual cycle variation ${ }^{25}$ or tissue atrophy at menopause, ${ }^{26}$ and variation by body type and ethnicity is unexplored.

We draw attention to the differences in vulval proportions and labial protuberance between the three imagery sources because medical professionals should ideally be able to communicate what constitutes the average range of female genital variation and be willing to discuss with patients how ideas about 'normality' arise. Sexual health training only constitutes 3-10 h in over $60 \%$ of North American medical schools surveyed, ${ }^{27}$ and there is some evidence that medical students feel their training in sexual health is inadequate. ${ }^{28} 29$ Thus, the non-specialist medical professionals who are likely to be consulted initially by women concerned about their genital appearance may lack the resources to provide satisfactory descriptions of normal variation. Though resources do exist for anatomical description to patients, ${ }^{30}$ a survey of the materials used in general and specialist gynaecological training would also be useful. In the absence of representational population norms, experience may give individual practitioners (especially specialists) their own ad hoc sample, but access to unbiased and representational depictions is also desirable, for clinical judgements and in advising patients who are seeking medical intervention for vulval morphologies that they perceive as abnormal. We have no information on surgeon characteristics that may be relevant, and further research should investigate the gender split of gynaecological surgeons, their age/training (as there may be historical trends in sexual health training), their exposure to different sources of variation and the materials they use to communicate 'normality' to patients. That a recent review ${ }^{3}$ found no preoperative comparisons with published norms ${ }^{11}$ in 937 cases is remarkable. These issues have further relevance in the consideration of surgery in intersex individuals and what might be considered the range of 'normal' (external) genital appearance. $^{31-33}$

We have very little information on the psychosocial processes and influences that shape (a) an individual's ideas about average and acceptable genital morphology and (b) the decision-making process to seek medical advice or intervention for their own appearance. In an online survey using line drawings of varied 
female genitalia, we found that women consistently rated all images less attractive than did men, ${ }^{34}$ consistent with earlier work. ${ }^{35}$ Women may arrive at judgements about their genitalia based on the comments of their sexual partners or friends, but patient questionnaire studies ${ }^{36} 37$ that have queried the reasons for labioplasty or other cosmetic genital surgery have concluded that outside influences were minimal. Decisions were attributed largely to functional (pain, discomfort) or personal/self-esteem reasons, often long-term concerns for many women, but these questionnaire studies did not attempt to elicit either patient's or surgeon's ideas of what is 'normal'. It is possible that personal dissatisfaction could be motivated by internalised body image concepts derived from, among other sources, visual imagery, ${ }^{38}$ but we stress here that this is a preliminary study, not evidence for any causal link between normative ideas derived from imagery and decisions to pursue genital surgery.

Rather, we hope that our results here may alert women and health professionals to the idea that not all observations might be equal. It can be argued that the internet is the most immediate and easily accessible ${ }^{13}$ source of information on genital morphology: it can be viewed privately and covertly, and carries no specific expenditure. On the one hand, a wide variety of informational, medical and feminist websites carry images of female genitalia, but on the other hand a large source of imagery on the internet comes from pornography. There is a need for quantitative and qualitative research to assess if the specific availability of pornography (online or otherwise) is construing people's ideas about normality and preferential morphology in the same way that mass media portrayals of female body shape has been linked to a normative ideal of thinness. ${ }^{39} 40$ This information, combined with accurate published norms and clear communication of the risks and benefits of surgery, should be available to all women who express worry about their genital appearance.

Disclaimer All authors had full access to all of the data (including statistical reports and tables) in the study and can take responsibility for the integrity of the data and the accuracy of the data analysis. Data sharing: the measurement dataset is available as an SPSS file to other researchers from the corresponding author.

\section{Competing interests None.}

Contributors All authors conceived and planned the study. $\mathrm{HH}$ collected the data. $\mathrm{HH}$ and $\mathrm{FJ}$ analysed the data. All authors wrote the manuscript.

Provenance and peer review Not commissioned; externally peer reviewed.

\section{REFERENCES}

1. Bramwell R, Morland C, Garden AS. Expectations and experience of labial reduction: a qualitative study. Obstet Gynecol Surv 2008;63:145-6.

2. Liao LM, Creighton SM. Requests for cosmetic genitoplasty: how should healthcare providers respond? BMJ 2007;334:1090-92. doi:10.1136/bmj.39206.422269.BE.

3. Liao LM, Michala L, Creighton SM. Labial surgery for well women: a review of the literature. BJOG 2010;117:20-5. doi:10.1111/j.1471-0528.2009.02426.x.

4. Braun V, Wilkinson S. Socio-cultural representations of the vagina. J Reprod Infant Psychol 2001:19:17-32.

5. Stewart EG, Spencer P. The V Book: A Doctors guide to complete vulvovaginal health. New York: Bantam Books, 2002.

6. Young ME, Norman GR, Humphreys KR. Medicine in the popular press: the influence of the media on perceptions of disease. PLOS ONE 2008;3:e3552. doi:10.1371/journal.pone.0003552.

7. Yanovitzky I, Blitz CL. Effect of media coverage and physician advice on utilization of breast cancer screening by women 40 years and older. $J$ Health Commun 2000;5:117-34

8. NHS Information Centre. Big increase in numbers of women undergoing cervical screening. http://www.ic.nhs.uk/news-and-events/press-office/press-releases/ big-increase-in-numbers-of-women-undergoing-cervical-screening laccessed 6 Nov 2009).

9. Duerksen S, Mikail A, Tom L, et al. Health disparities and advertising content of women's magazines: a cross-sectional study. BMC Public Health 2005;5:85. doi:10.1186/1471-2458-5-85.

10. Joyner BL, Gill-Bailey C, Moon RY. Infant sleep environments depicted in magazines targeted to women of childbearing age. Pediatrics 2009;124:e416-22. doi:10.1542/peds.2008-3735

11. Lloyd J, Crouch NS, Minto CL, et al. Female genital appearance:'normality' unfolds. BJOG 2005;112:643-46. doi:10.1111/j.1471-0528.2004.00517.x.

12. Bsaran M, Kosif R, Bayar U, et al. Characteristics of external genitalia in pre- and postmenopausal women. Climacteric 2008;11:416-21.

13. Alexa Internet. Top Sites. http://www.alexa.com/site/ds/top_sites?cc=GB\&; ts mode=country (accessed 4 Jun 2008).

14. RedTube. http://www.redtube.com (accessed 23 May 2008)

15. YouPorn. http://www.youporn.com (accessed 25 May 2008).

16. PornHub. http://www.pornhub.com (accessed 22 May 2008).

17. Vulvology. http://www.erogenousdot.com 1999 (accessed 21 May 2008).

18. Karras N. Petals. Korea: Crystal River Publishing, 2003.

19. Blank J, Corinne T. Femalia. San Francisco: Down There, 1993.

20. McCartney J. Design a vagina. http://www.brightonbodycasting.com/design-avagina.php 2009 (accessed 17 Jun 2009)

21. Dumesic DA, Schramm RD, Peterson E, et al. Impaired developmental competence of oocytes in adult prenatally androgenized female rhesus monkeys undergoing gonadotropin stimulation for in vitro fertilization. J Clin Endocrinol Metab 2002;87:1111-19.

22. Maas SM, Hage JJ. Functional and aesthetic labia minora reduction. Plast Reconst Surg 2000;105:1453-6

23. Schick VR, Rima BN, Calabrese SK. Evulvalution: the portrayal of women's external genitalia and physique across time and the current Barbie Doll ideals. J Sex Res Published online First 2010. doi:10.1080/00224490903308404.

24. New View Campaign. Vulvagraphics: an intervention in honor of female genital diversity. http://www.newviewcampaign.org/vulvagraphics.asp 2008 (accessed 11 Nov 2009)

25. Eschenbach DA, Thwin SS, Patton DL, et al. Influence of the normal menstrual cycle on vaginal tissue, discharge, and microflora. Clin Infect Dis 2000;30:901-7.

26. Farage M, Maibach $\mathrm{H}$. Lifetime changes in the vulva and vagina. Arch Gynecol Obstet 2006:273:195-202.

27. Solursh DS, Ernst JL, Lewis RW, et al. The human sexuality education of physicians in North American medical schools. Int J Impot Res 2003;15:S41-5.

28. Wittenberg A, Gerber J. Recommendations for improving sexual health curricula in medical schools: results from a two-arm study collecting data from patients and medical students. J Sex Med 2009;6:362-8. doi:10.1111/j.1743-6109.2008.01046.x.

29. Parish SJ, Clayton AH. Sexual medicine education: review and commentary (CME) J Sex Med 2007;4:259-68. doi:10.1111/j.1743-6109.2007.00430.x.

30. O'Connell HE, Eizenberg N, Rahman $\mathrm{M}$, et al. The anatomy of the distal vagina: towards unity. J Sex Med 2008;5:1883-91.

31. Karkazis K. Fixing Sex: Intersex, Medical Authority, and Lived Experience. Durham, NC: Duke University Press, 2008.

32. Dreger A, Feder EK. Bad Vibrations. BioEthics Forum: The Hastings Center, http://www.thehastingscenter.org/Bioethicsforum/Post.aspx?id=4730\&;blogid=140 2010 (accessed 19 Jun 2010).

33. Hrabovszky Z, Hutson JM. Surgical treatment of intersex abnormalities: a review Surgery 2002;131:92-104.

34. Howarth HM. Male Choice: Potential Male Preferences For Female External Genital Morphology. Unpublished thesis, UCL, 2008.

35. Reinholtz RK, Muehlenhard CL. Genital perceptions and sexual activity in a college population. J Sex Res 1995;32:155-65.

36. Miklos JR, Moore RD. Labiaplasty of the labia minora: patients indications for pursuing surgery. J Sex Med 2008;5:1492-95. doi:10.1111/J.1743-6109.2008.00813.X.

37. Goodman MP, Placik OJ, Benson $\mathrm{RH}$, et al. A large multicenter outcome study of female genital plastic surgery. J Sex Med 2010;7:1565-77. doi:10.1111/j.1743-6109.2009.01573.x.

38. Groskop V. A Cut Too Far: The Rise In Cosmetic Surgery On Female Genitalia Guardian, 2009.

39. Levine MP, Murnen SK. "Everybody knows that mass media are/are not [pick one a cause of eating disorders": a critical review of evidence for a causal link between media, negative body image, and disordered eating in females. J Soc Clin Psychol 2009;28:9-42.

40. Grabe S, Ward LM, Hyde JS. Role of the media in body image concerns among women: a meta-analysis of experimental and correlational studies. Psychol Bull 2008:134:460-76. 